\title{
Analisis Pemilihan Mata Kuliah Praktek Menggunakan Metode AHP
}

\author{
Zulfi Azhar \\ Sekolah Tinggi Manajemen Informatika Komputer Royal \\ Jl. Prof.H.M.Yamin No.173, Kisaran, Sumatera Utara, Indonesia, 21222 Telp.(0623) 41079 \\ E-mail :zulfi_azhar@yahoo.co.id
}

\begin{abstract}
Practical courses in the laboratory are scheduled according to the institutional curriculum. In determining the choice of practice courses, the STMIK Royal Kisaran information system study program requires a system of analysis in the selection of practical subjects that provide the best choices based on the required criteria. Priority criteria are important data in the process of determining the selection of the course. This is needed to gain knowledge for study programs in the use of schedules and choice of priority practice courses. This research is a continuation of factor analysis in the selection of practice subjects where the information system study program uses the Analytical Hierarchy Process (AHP) method. From the results of the analysis, it is obtained the selection of priority practice courses from several alternatives that can be useful for study programs based on priority criteria.
\end{abstract}

Keywords: AHP, alternatives, criteria, practice subjects, study program

\begin{abstract}
Abstrak-Matakuliah praktek di laboratorium dijadwalkan sesuai dengan kurikulum institusi. Dalam menentukan pemilihan matakuliah praktek, Program studi sistem informasi STMIK Royal Kisaran memerlukan suatu sistem analisis dalam pemilihan matakuliah praktek yang memberikan pilihan terbaik berdasarkan kriteria yang diperlukan. Faktor kriteria yang prioritas merupakan data yang penting dalam memproses penentukan pemilihan matakuliah tersebut. Hal ini diperlukan untuk mendapatkan pengetahuan bagi prodi dalam penggunaan jadwal dan pilihan mata kuliah praktek prioritas. Penelitian ini sebagai kelanjutan dari analisis faktor dalam pemilihan matakuliah praktek dimana prodi sistem informasi menggunakan metode Analytical Hierarchy Process (AHP). Dari hasil analisis maka diperoleh pemilihan prioritas pemilihan matakuliah praktek dari beberapa alternatifyang dapat bermanfaat bagi prodi berdasarkan faktor prioritas kriteria.
\end{abstract}

Kata kunci: AHP, alternatif, kriteria, matakuliah praktek, prodi

\section{PENDAHULUAN}

Matakuliah praktek di laboratorium dijadwalkan sesuai dengan kurikulum institusi. Dalam menentukan pemilihan matakuliah praktek, Prodi Sistem Informasi STMIK Royal Kisaran memerlukan suatu sistem analisis dalam pemilihan matakuliah praktek yang memberikan pilihan terbaik berdasarkan kriteria yang diperlukan. Faktor kriteria yang prioritas merupakan data yang penting dalam memproses penentukan pemilihan matakuliah tersebut. Hal ini diperlukan untuk mendapatkan pengetahuan bagi Prodi dalam penggunaan jadwal dan pilihan mata kuliah praktek prioritas. Penelitian ini sebagai kelanjutan dari analisis faktor dalam pemilihan matakuliah praktek Prodi sistem informasi dengan menggunakan metode Analytical Hierarchy Process (AHP). Dari hasil analisis pemilihan prioritas kriteria akan mendapatkan prioritas kriteria yang terbaik dan selanjutnya dengan beberapa alternatif matakuliah praktek yang ditentukan maka 
akan didapatkan matakuliah yang prioritas yang merupakan alternatif mata kuliah paktek yang terbaik. Dengan penelitian ini prodi akan mendapat pengetahuan dalam mendapatkan hasil pemilihan dengan menggunakan sistem pendukung keputusan yang lebih cerdas dan efektif.

\section{METODOLOGI PENELITIAN}

Tahap - tahap yang dilakukan dalam penelitian ini yaitu :

a. Pengumpulan Data

Pengumpulan data dilakukan di STMIK Royal Kisaran, berupa form matriks penilaian dan selanjutnya untuk dapat diproses analisis datanya.

b. Analisis Data

Tahapan ini menganalisa dan merancang sistem yang akan digunakan dengan prioritas dari kriteria yang ditentukan dalam mendapatkan beberapa alternatif pilihan.

c. Pengujian Menggunakan Sistem

Pada tahapan ini akan diuji dengan menggunakan tools Super Decission, pengujian sistem dilakukan dengan cara memvalidasi perhitungan metode AHP yang dilakukan secara manual dengan dibandingkan dengan perhitungan yang ada di sistem.

\subsection{Sistem Pendukung Keputusan}

Sistem Pendukung Keputusan dapat juga juga diartikan sebagai sistem komputer yang mengolah data menjadi informasi untuk mengambil keputusan dari masalah semi-terstruktur yang spesifik(1). Decision Support System (DSS) lebih ditunjukkan untuk mendukung menejemen dalam melakukan pekerjaan yang bersifat analitis dalam situasi yang kurang terstruktur dan dengan kriteria yang kurang jelas. DSS tidak dimaksudkan untuk tidak mengotomatisasikan pengambilan keputusan, tetapi memberikan perangkat interaktif yang memungkinkan pengambil keputusan untuk melakukan berbagai analisis menggunakan model-model yang tersedia(8).

\subsection{Analytical hierarchy Process (AHP)}

Pada dasarnya, proses pengambilan keputusan adalah memilih suatu alternatif. Peralatan utama AHP adalah sebuah hirarki fungsional dengan masukan utamanya adalah persepsi manusia. Keberadaan hirarki memungkinkan dipecahnya masalah kompleks atau tidak terstruktur dalam sub-sub masalah, lalu menyusunnya menjadi suatu bentuk hirarki. AHP memiliki banyak keunggulan dalam menjelaskan proses pengambilan keputusan. Salah satunya adalah dapat digambarkan secara grafis sehingga mudah di pahami oleh semua pihak yang terlibat dalam pengambilan keputusan.

\subsection{Prosedur AHP}

Langkah-langkah dalam metode AHP meliputi:

a. Mendefinisikan masalah dan menentukan solusi yang diinginkan, lalu menyusun hirarki dari permasalahan yang dihadapi. 
Menyusun hirarki adalah kemampuan manusia untuk mempersepsikan benda dan gagasan, mengidentifikasikannya, dan mengkomunikasikan apa yang mereka amati. Untuk memperoleh pengetahuan terinci, pikiran kita menyusun realitas yang kompleks kedalam bagian yang menjadi elemen pokoknya, dan kemudian bagian ini dibagi kedalam bagian-bagiannya lagi, dan seterusnya secara hierarki[6].

b. Menentukan prioritas elemen

Langkah pertama dalam menentukan prioritas elemen adalah membuat matriks perbandingan pasangan. Matriks perbandingan berpasangan diisi menggunakan bilangan untuk mempresentasikan kepentingan relatif dari suatu elemen terhadap elemen yang lainnya.

c. Sintesis

Pertimbangan-pertimbangan terhadap perbandingan berpasangan disintesis untuk memperoleh keseluruhan prioritas.

d. Mengukur konsistensi

Dalam pembuatan keputusan, penting untuk mengetahui seberapa baik konsistensi yang ada karena kita tidak menginginkan keputusan berdasarkan pertimbangan dengan konsistensi yang rendah. Hal-hal yang dilakukan dalam langkah ini adalah:

1. Hitung Consistency Index (CI)

$$
\mathrm{CI}=(\lambda \text { maks }-\mathrm{n}) / \mathrm{n}-1
$$

Keterangan:

$\mathrm{n}=$ banyaknya elemen

$\lambda$ maks $=$ nilai eigen maksimum dari matriks pairwise comparisons

2. Hitung Rasio Konsistensi/Consistency Ratio (CR)

$\mathrm{CR}=\mathrm{CI} / \mathrm{RI}$

Keterangan:

$\mathrm{CR}=$ Consistency Ratio,

$\mathrm{CI}=$ Consistency Index,

$\mathrm{RI}=$ Random Index

3. Memeriksa konsistensi hirarki.

Jika nilainya lebih dari 10\%, maka penilaian data judgment harus diperbaiki. Namun jika rasio konsistensi (CI/IR) kurang atau sama dengan 0,1, (CR < $0,1)$ maka hasil perhitungan bisa dinyatakan benar.

$$
\mathrm{CR}<0,1
$$


Tabel 1. Skala Penilaian Hierarki

\begin{tabular}{|c|c|c|}
\hline $\begin{array}{c}\text { Intensitas } \\
\text { Kepentingan }\end{array}$ & $\begin{array}{l}\text { Definisi } \\
\text { Variabel }\end{array}$ & Penjelasan \\
\hline 1 & Sama pentingnya & kedua elemen mempunyai pengaruh yang sama \\
\hline 3 & $\begin{array}{l}\text { Sedikit lebih } \\
\text { penting }\end{array}$ & $\begin{array}{l}\text { kategori sedang dibandingkan dengan kepentingan } \\
\text { lainnya }\end{array}$ \\
\hline 5 & Lebih penting & $\begin{array}{l}\text { kategori lebih dibandingkan dengan kepentingan } \\
\text { lainnya }\end{array}$ \\
\hline 7 & Sangat penting & $\begin{array}{l}\text { kategori amat kuat dibandingkan dengan kepentingan } \\
\text { lainnya }\end{array}$ \\
\hline 9 & $\begin{array}{l}\text { Mutlak } \\
\text { penting }\end{array}$ & $\begin{array}{l}\text { kepentingan satu secara ekstrim lebih kuat dari } \\
\text { kepentingan lainnya }\end{array}$ \\
\hline
\end{tabular}

Sedangkan skala 2,4,6,8 = nilai diantara dua penilaian yang berdekatan. Prioritas kriteria terbaik dari total rangking yang diperoleh merupakan rangking yang dicari dalam Analytical Hierarchy Process (AHP) ini.

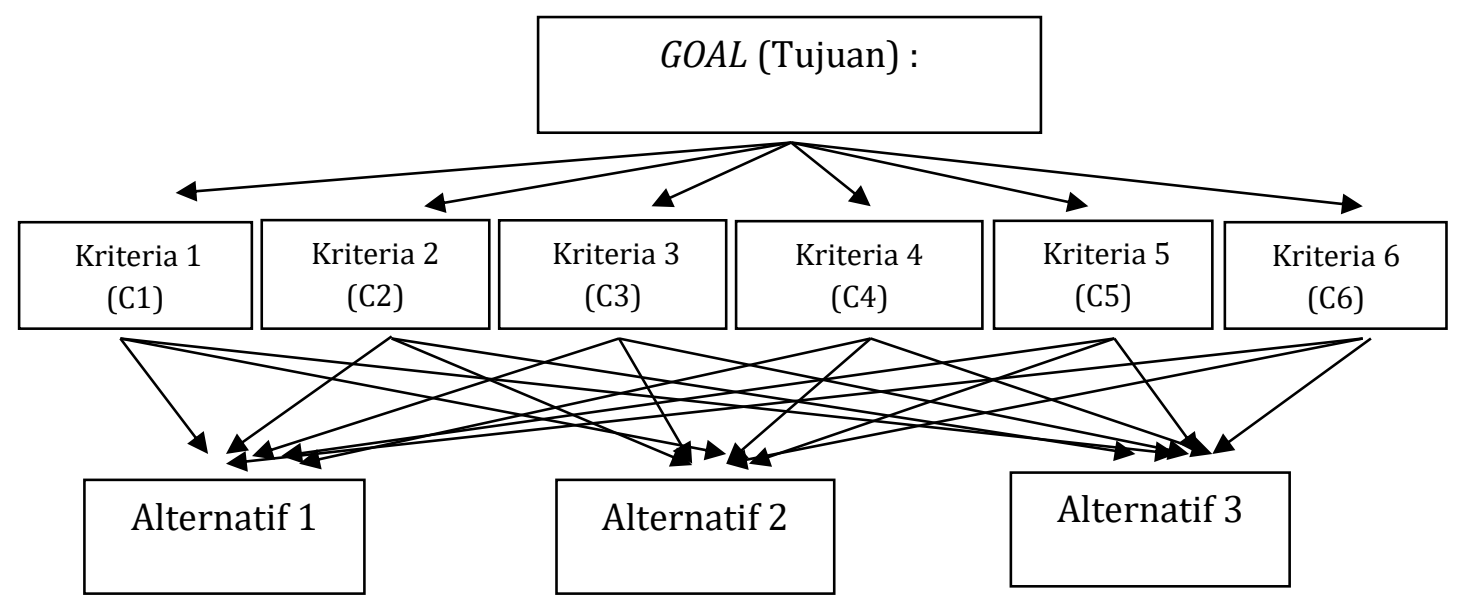

Gambar 1. Struktur Hierarki Kriteria Prioritas Pada Pemilihan Matakuliah Praktek

\section{HASIL DAN PEMBAHASAN}

Data dikumpulkan di kampus STMIK Royal Kisaran dengan melibatkan para mahasiswa/i, dengan menggunakan sejumlah formulir penilaian. Data pada formulir penilaian lalu diproses dan dianalisis. Dari hasil penilaian beberapa kriteria yang mempengaruhi dalam pemilihan matakuliah praktek di laboratorium yaitu : Pemahaman Program (C1), Pemahaman Teori (C2), Pengajar/Dosen (C3), Tugas Praktek (C4), Waktu Praktek (C5) dan Modul Pembelajaran (C6). 


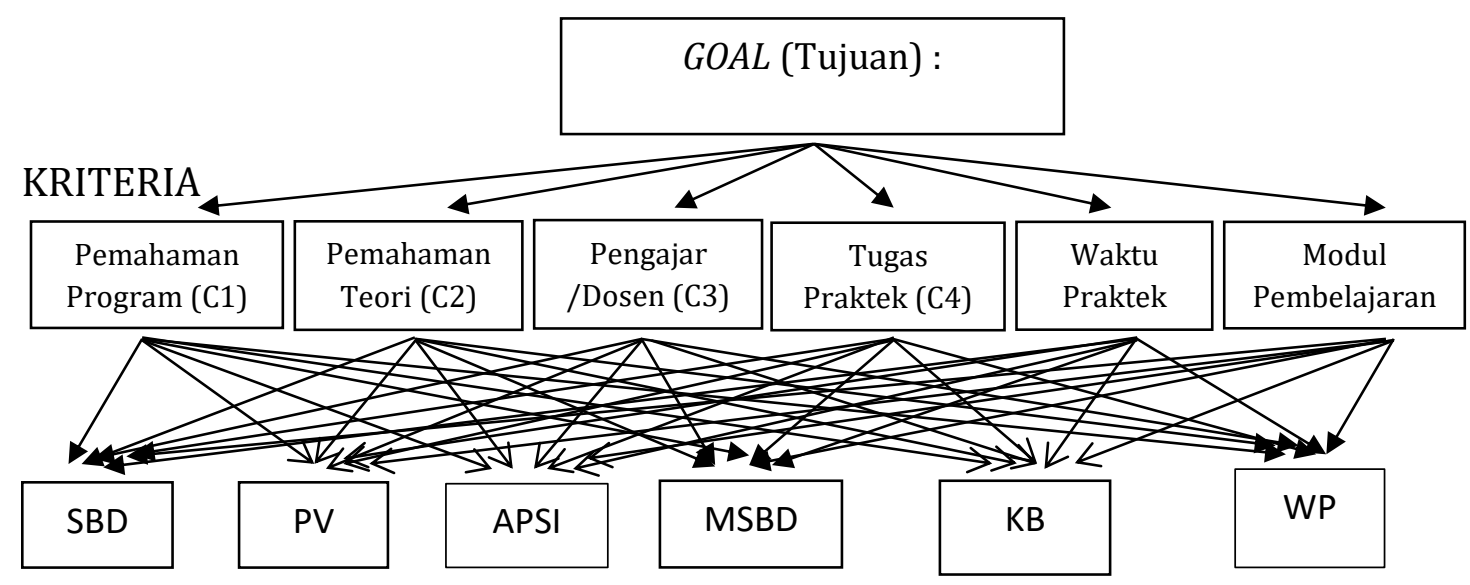

ALTERNATIF

Gambar 2. Struktur Hierarki Kriteria Prioritas Pada Pemilihan Matakuliah Praktek

Tabel 2. Sintesis Matriks Perbandingan Kriteria

\begin{tabular}{|l|l|l|l|l|l|l|}
\hline & C1 & C2 & C3 & C4 & C5 & C6 \\
\hline C1 & 1 & 3 & 3 & 3 & 3 & 5 \\
\hline C2 & 0,333 & 1 & 3 & 2 & 3 & 5 \\
\hline C3 & 0,333 & 0,333 & 1 & 0,333 & 0,50 & 3 \\
\hline C4 & 0,333 & 0,50 & 3 & 1 & 0,333 & 3 \\
\hline C5 & 0,333 & 0,333 & 2 & 3 & 1 & 3 \\
\hline C6 & 0,20 & 0,20 & 0,333 & 0,333 & 0,333 & 1 \\
\hline Jumlah & 2,533 & 5,367 & 12,333 & 9,667 & 8,167 & 20 \\
\hline
\end{tabular}

Tabel 3. Normalisasi Kriteria

\begin{tabular}{|l|l|l|l|l|l|l|l|}
\hline & C1 & C2 & C3 & C4 & C5 & C6 & Jumlah \\
\hline C1 & 0,395 & 0,559 & 0,243 & 0,310 & 0,367 & 0,250 & 2,125 \\
\hline C2 & 0,132 & 0,186 & 0,243 & 0,207 & 0,367 & 0,250 & 1,385 \\
\hline C3 & 0,132 & 0,062 & 0,081 & 0,034 & 0,061 & 0,150 & 0,520 \\
\hline C4 & 0,132 & 0,093 & 0,243 & 0,103 & 0,041 & 0,150 & 0,762 \\
\hline C5 & 0,132 & 0,062 & 0,162 & 0,310 & 0,122 & 0,150 & 0,939 \\
\hline C6 & 0,079 & 0,037 & 0,027 & 0,034 & 0,041 & 0,050 & 0,269 \\
\hline Jumlah & 1 & 1 & 1 & 1 & 1 & 1 & 6 \\
\hline
\end{tabular}

Tabel 4. Persentase dan Rangking Prioritas

\begin{tabular}{|c|l|l|l|}
\hline Kriteria & Prioritas & Persentase Prioritas & Rangking Prioritas \\
\hline C1 & 0,354 & 35,4 & 1 \\
\hline C2 & 0,231 & 23,1 & 2 \\
\hline C3 & 0,087 & 8,7 & 5 \\
\hline C4 & 0,127 & 12,7 & 4 \\
\hline C5 & 0,156 & 15,6 & 3 \\
\hline C6 & 0,045 & 4,5 & 6 \\
\hline Jumlah & 1 & 100 & \\
\hline
\end{tabular}


Nilai pada masing - masing kriteria tersebut dinyatakan benar atau konsisten sebelum terpenuhinya nilai Consistency Ratio (CR) $<0,1$. Rasio Konsistensi/Consistency Ratio (CR) dapat dihitung dengan rumus: $\mathrm{CR}=\mathrm{CI} / \mathrm{IR}$

Keterangan:

$\mathrm{CR}=$ Consistency Ratio

$\mathrm{CI}=$ Consistency Index

$\mathrm{RI}=$ Random Index

$\mathrm{CI}=(\lambda$ maks-n $) / \mathrm{n}-1$

Keterangan:

$\mathrm{N} \quad=$ banyaknya elemen

$\lambda$ maks $=$ nilai eigen maksimum dari matriks pairwise comparisons.

Nilai eigen maksimum ( $\lambda$ maksimum) diperoleh dengan menjumlahkan hasil perkalian jumlah pada kolom sintesis matriks perbandingan kriteria pada tabel 2 dengan kolom prioritas pada tabel 4. Maka nilai eigen maksimum adalah:

$\lambda$ maks $=\left(2,533^{*} 0,354\right)+(5,367 * 0,231)+\left(12.333^{*} 0,087\right)+(9,667 * 0,127)+$ $(8,167 * 0,156)+(20 * 0,045)=6,60694$

$\mathrm{CI}=(6,60694-6) / 6-1=0,12139$

Tabel 5. Random Index (RI)

\begin{tabular}{|l|l|l|l|l|l|l|l|l|l|l|l|l|l|l|}
\hline $\mathrm{n}$ & 1,2 & 3 & 4 & 5 & 6 & 7 & 8 & 9 & 10 & 11 & 12 & 13 & 14 & 15 \\
\hline $\mathrm{RI}$ & 0 & 0,58 & 0,90 & 1,12 & 1,24 & 1,32 & 1,41 & 1,45 & 1,49 & 1,51 & 1,48 & 1,56 & 1,57 & 1,59 \\
\hline
\end{tabular}

Dalam menetukan nilai RI berdasarkan dari jumlah kriteria (n). Jumlah kriteria ada 6 sehingga $\mathrm{n}=6$, maka nilai $\mathrm{RI}=1,24$ sesuai pada tabel Random Index (RI). Maka selanjutnya menentukan nilai CR.

$\mathrm{CR}=\mathrm{CI} / \mathrm{IR}=0,12139 / 1,24=0,0979$.

Maka Nilai $\mathrm{CR}=0,0979$ dan memenuhi syarat, dimana $\mathrm{CR}<0,1$ sehingga dapat dgambarkan bahwa proses penentuan prioritas kriteria yang mempengaruhi pemilihan matakuliah praktek dapat dinyatakan konsisten/benar.

Selanjutnya dengan menentukan matriks perbandingan alternatif dengan satu kriteria. Pada jasus ini dicontohkan perbandingan alternatif dengan kriteria pemahaman program (C1).

Beberapa alternatif dalam pemilihan matakuliah praktek di laboratorium yaitu : Sistem Basis Data (A1), Pemograman Visual (A2), Analisis dan Perancangan Sistem Informasi (A3), Manajemen Sistem Basis Data (A4), Kecerdasan Buatan (A5) dan Web Programming (A6).

Tabel 6. Sintesis Matriks Perbandingan Alternatif

\begin{tabular}{|l|c|c|c|c|c|c|}
\hline & A1 & A2 & A3 & A4 & A5 & A6 \\
\hline
\end{tabular}




\begin{tabular}{|l|l|l|l|l|l|l|}
\hline & \multicolumn{1}{|c|}{ A1 } & \multicolumn{1}{|c|}{ A2 } & \multicolumn{1}{|c|}{ A3 } & \multicolumn{1}{|c|}{ A4 } & \multicolumn{1}{|c|}{ A5 } & \multicolumn{1}{|c|}{ A6 } \\
\hline A1 & 1 & 2 & 3 & 0,5 & 2 & 0,5 \\
\hline $\mathbf{A 2}$ & 0,500 & 1 & 2 & 0,5 & 0,5 & 1 \\
\hline $\mathbf{A 3}$ & 0,333 & 0,500 & 1 & 0,333 & 0,333 & 0,333 \\
\hline $\mathbf{A 4}$ & 2 & 2 & 3 & 1 & 0,5 & 2 \\
\hline $\mathbf{A 5}$ & 0,5 & 2 & 3 & 2 & 1 & 0,5 \\
\hline $\mathbf{A 6}$ & 2 & 1 & 3 & 0,5 & 2 & 1 \\
\hline Jumlah & 6,333 & 8,5 & 15 & 4,833 & 6,333 & 5,333 \\
\hline
\end{tabular}

Tabel 7. Normalisasi Alternatif

\begin{tabular}{|l|l|l|l|l|l|l|l|}
\hline & \multicolumn{1}{|c|}{ A1 } & \multicolumn{1}{|c|}{ A2 } & \multicolumn{1}{|c|}{ A3 } & \multicolumn{1}{|c|}{ A4 } & A5 & \multicolumn{1}{|c|}{ A6 } & Jumlah \\
\hline A1 & 0,158 & 0,235 & 0,200 & 0,103 & 0,316 & 0,094 & 1,106 \\
\hline A2 & 0,079 & 0,118 & 0,133 & 0,103 & 0,079 & 0,188 & 0,700 \\
\hline A3 & 0,053 & 0,059 & 0,067 & 0,069 & 0,053 & 0,063 & 0,362 \\
\hline A4 & 0,316 & 0,235 & 0,200 & 0,207 & 0,079 & 0,375 & 1,412 \\
\hline A5 & 0,079 & 0,235 & 0,200 & 0,414 & 0,158 & 0,094 & 1,180 \\
\hline A6 & 0,316 & 0,118 & 0,200 & 0,103 & 0,316 & 0,188 & 1,240 \\
\hline Jumlah & 1 & 1 & 1 & 1 & 1 & 1 & 6 \\
\hline
\end{tabular}

Tabel 8. Persentase dan Rangking Prioritas

\begin{tabular}{|c|l|l|l|}
\hline Kriteria & Prioritas & Persentase Prioritas & Rangking Prioritas \\
\hline A1 & 0,184 & 18,4 & 4 \\
\hline A2 & 0,117 & 11,7 & 5 \\
\hline A3 & 0,060 & 6 & 6 \\
\hline A4 & 0,235 & 23,5 & 1 \\
\hline A5 & 0,197 & 19,7 & 3 \\
\hline A6 & 0,207 & 20,7 & 2 \\
\hline Jumlah & 1 & 100 & \\
\hline
\end{tabular}

Nilai eigen maksimum ( $\lambda$ maksimum) dapat diperoleh dengan menjumlahkan hasil perkalian jumlah pada kolom sintesis matriks perbandingan alternatif pada tabel 6 dengan kolom prioritas pada tabel 8. Maka nilai eigen maksimum adalah: $\lambda$ maks $=\left(6,333^{*} 0,184\right)+(8,5 * 0,117)+\left(15^{*} 0,060\right)+\left(4,833^{*} 0,235\right)+$ $(6,333 * 0,197)+(5,333 * 0,207)=6,54957$

$C I=(6,54957-6) / 6-1=0,10991$

Dalam menetukan nilai RI berdasarkan dari jumlah alternatif (n). Jumlah alternatif ada 6 sehingga $\mathrm{n}=6$, maka nilai $\mathrm{RI}=1,24$ sesuai pada tabel Random Index (RI). Maka selanjutnya menentukan nilai CR.

$\mathrm{CR}=\mathrm{CI} / \mathrm{IR}=0,10991 / 1,24=0,08864$.

Maka Nilai $\mathrm{CR}=0,08864$ dan memenuhi syarat, dimana $\mathrm{CR}<0,1$ sehingga dapat proses penentuan pemilihan matakuliah praktek dapat dinyatakan konsisten/benar.

Maka hasil akhir dari implementasi dan pengujian sistem pemilihan matakuliah praktek berdasarkan pemahaman program adalah Alternatif ke-4 (A4) yang terpilih menurut kriteria yang ada. 


\section{KESIMPULAN}

Adapun kesimpulan yang dapat diambil dalam penelitian ini adalah:

a. Metode Analytical Hierarchy Proces (AHP) dapat membantu menganalisis dalam pemilihan matakuliah praktek di STMIK Royal Kisaran.

b. Kriteria yang diproses memberikan satu bentuk form format penilaian yang dapat berdampak untuk mengurangi kesalahan dalam memberikan dan menentukan penilaian.

c. Metode AHP dapat membantu menganalisis faktor/kriteria prioritas dalam memilih matakuliah praktek di STMIK Royal Kisaran.

\section{Daftar Pustaka}

[1] Andayati, Dina. (2010). Sistem Pendukung Keputusan Pra-Seleksi Penerimaan Mahasiswa Baru (PSB) Online Yogyakarta. Jurnal Teknologi. Vol 3 No 2. hal 145-153.

[2] Azhar, Z dan Handayani, M. Analisis Faktor Prioritas Dalam Pemilihan Perumahan KPR Menggunakan Metode AHP. Jurnal Manajemen Informatika \& Sistem Informasi (MISI) ISSN : 2614-1701. Volume 1 No 22018 hal : 19-22

[3] Azhar, Z dan Handayani, M. Analisis Pemilihan Perumahan KPR Menggunakan Metode AHP. Proceeding Seminar Nasional Royal (SENAR) ISBN 2622-9986. Vol,1 No.1 hal 51-54

[4] Davis, Ralp C dalam Hasan. (2004). Pokok-pokok Materi Teori Pengambilan Keputusan. Jakarta: Ghalia Indonesia.

[5] Makkasau, K. (2013). Penggunaan metode Analytic Hierarchy Process (AHP) dalam penentuan prioritas program kesehatan (studi kasus program Promosi Kesehatan). J@ ti Undip: Jurnal Teknik Industri, 7(2), 105-112.

[6] Saaty, T.L., 1990, The Analytic Hierarchy Process, McGraw-Hill, New York.

[7] Sembiring, M. A. (2017). Penerapan Metode Simple Additive Weighting Sebagai Strategi Pembinaan Kecerdasan Anak. JURTEKSI, 4(1), 65-70.

[8] Susilo, W.R., dan Munadi, E., (2011). Penggunaan Analitycal Hierarchy Process Untuk penyusunan prioritas proposal penelitian, Jurnal Informatika Pertanian. No. 2, Volume 16.

[9] Widara, Priranda. 2013. Sistem Pendukung Keputusan Dalam Penilaian Kinerja Pegawai Untuk Kenaikan Jabatan Pegawai Menggunakan Metode Gap Kompetensi(Studi Kasus Perusahaan Perkasa Jaya Compuretail). Jurnal Sarjana Teknik Informatika. ISSN: 2338-5197. Vol 1 No.2. hal. 574-583.

[10] Khairul Imtihan. "Perencanaan Strategi Sistem Informasi Pendidikan Pada Sekolah Tinggi Manajemen Informatika dan Komputer (STMIK) Lombok." Bianglala Informatika 3.2 (2015).

[11] Zaen, M. Taufan Asri, Sunaryo Sunaryo, and Wijono Wijono. "Sistem Pendukung Keputusan untuk Investasi Perumahan Area Malang Menggunakan P Algoritma Bayesian." Jurnal EECCIS 8.1 (2014): $13-18$ 